\title{
LA LEY DEL DESCANSO DOMINICAL EN SALÓNICA: IMPACTO EN LA COMUNIDAD JUDÍA A TRAVÉS DE LA PRENSA FRANCÓFONA (1924-1925)
}

\author{
Matilde Morcillo Rosillo \\ Universidad de Castilla - La Mancha. España
}

Resumen: Este trabajo es una aproximación al estudio de la comunidad judía de Salónica en el marco de la república griega, deteniéndonos en la repercusión que tuvo sobre dicha comunidad la implantación de la Ley del descanso dominical obligatorio en Salónica por el gobierno republicano de Papanastasíu en 1924. Los diarios judíos L'Indépendant y Le Progrès, principalmente, consideraron la medida como un atentado a la libertad de conciencia de los judíos y a sus intereses nacionales. Algunas asociaciones, sin embargo, llegaron más lejos al hablar de persecución y antisemitismo.

Palabras clave: L'Indépendant - Le Progrès - sabat - judíos - descanso - Papanastasíu Venizelos

\section{THE QUESTION OF THE SUNDAY REST IN SALONIKA: IMPACT ON THE JEWISH COMMUNITY THROUGH THE FRANCOPHONE PRESS (1924-1925)}

Abstract: This work is an approach to the study of the Jewish community of Thessaloniki in the framework of the Greek Republic, focusing on the repercussion that it had on this community the implementation of the Law of the compulsory Sunday rest in Thessaloniki by the Republican government of Papanastasiou in 1924. The Jews newspaper Le Progrès and L'Indépendant, mainly, considered the measure as an attack on freedom of conscience of the Jews and their national interests. Some associations, however, went further by speaking of persecution and anti-Semitism.

Key words: L'Indépendant - Le Progrès - Sabbath - Jews - rest - Papanastasiou - Venizelos

Recibido: 13.06.13 - Aceptado: 23.09.2013

Correspondencia: Matilde Morcillo Rosillo,

E mail: Matilde.MRosillo@uclm.es

Profesora titular de Historia Contemporánea Facultad de Educación (Albacete)

Universidad de Castilla-La Mancha Plaza de la Universidad, 302071 Albacete (Espańa)

Telf. + 34967 234754. Fax: + 967599229 


\section{LA LEY DEL DESCANSO DOMINICAL EN SALÓNICA}

1.

El tema ya ha sido abordado por otros investigadores ${ }^{1}$, por ello, el presente estudio se basa solamente en lo publicado en la prensa francófona de Salónica ${ }^{2}$, aunque también se hacen referencias a la prensa griega. Los nombres propios griegos han sido transcritos al castellano, los de las instituciones judías aparecen con la misma grafía que en la prensa francesa.

La prensa francófona de Salónica hace su aparición tardíamente a finales del siglo XIX 3 . Sin embargo, hacia 1900 Salónica contaba ya al menos con cuatro órganos en francés: L'Indépendant, Le Journal de Salonica, Le Progrès de Salonica y un periódico probablemente destinado a la juventud: L'Ecole y La Famille. Algunos años más tarde, en el momento de la revolución de los jóvenes turcos en 1908, aparece súbitamente una decena de nuevos periódicos, que no debieron sobrevivir más allá de los primeros instantes de euforia ${ }^{4}$.

Salónica abordará la Primera Guerra Mundial con una prensa de expresión francesa importante, destacando entre ellos La Liberté, órgano del gobierno

${ }^{1}$ El tema del descanso dominical en Salónica ha sido estudiado entre otros por Pierron, B.; Molho, R.; Josua Elli, P.; Linfield, H.S. etc.

${ }^{2}$ Dumont. P. (1993). «Le français d'abord», en Salonique 1850-1918. La «ville des juifs» et le réveil des Balkans, (dir.) Veinstrin, G. Paris, 208-210.

3 Sobre la prensa en los Balcanes pueden verse las obras de Romero, E. (2007) "La prensa judeoespañola contra los recelos, la burocracia y la censura", en Ayer y hoy de la prensa en judeoespañol, (eds.) Pablo Martín Asuero y Karen Gerson Sarhon. Isis, Estambul; Romero. E. (2008) Entre dos (o más) fuegos: Fuentes poéticas para la historia de los sefardies de los Balcanes, C.S.I.C. Madrid, 731; 9-10; Díaz-Mas, P. (2007). "Relaciones entre la prensa española y la prensa sefardí a finales del siglo XIX: El caso del Luzero de la pasensia", en Ayer y hoy de la prensa en judeoespañol, 38-39; Morcillo, M. (1991). "Hispania, primera revista española en Oriente (1919)" Ensayos 5, Escuela de Magisterio, Albacete, 71-77 y (1997). "España y la prensa judeoespañola en Salónica durante el primer tercio del siglo XX", en Ayer y hoy de la prensa en judeoespañol, 47-57.

4 Rodrigue, A. (1989). De l'instruction à l'émancipation. Les enseignants de l'Alliance Israélite Universelle et les Juifs d'Orient, 1860-1939, Paris; Dumont. P. (1993). «Le français d'abord», en Salonique 1850-1918. La "ville des juifs» et le réveil des Balkans, 208-210; Nehama, J. (1978). Histoire des Israélites de Salonique, VI-VII, Salonique. 
griego, L'Indépendant, que se jactaba de ser el más antiguo diario de lengua francesa aparecido en la región, Le Progrès y L'Opinion, el más importante este último entre el mundo comercial y financiero de Macedonia, Tracia, Epiro y la Nueva Serbia ${ }^{5}$.

\subsection{Contexto histórico}

Antes de las guerras balcánicas (1912-1913), los judíos procedentes de España, tras la expulsión en 1492, gozaban de un clima de tolerancia en el Imperio otomano; por su parte, los judíos que vivían en Grecia desde la antigüedad (romaniotas)también disfrutaban de unos derechos otorgados por la Constitución griega en 1864, independientemente de su raza o religión.

Dada la evolución económica de la capital de Macedonia (Salónica), hasta 1900 la competencia económica entre judíos y no judíos no llegó a perturbar el clima de buen entendimiento que reinaba en la ciudady que se rompería por motivos políticos, pues los judíos eran hostiles a la agitación revolucionaria que reinaba en Macedonia y solo deseaban el mantenimiento del statu quo. Tal actitud disgustaría a los irredentistas del territorio macedónico y su capital, y aunque parecía poco probable que los judíos de Salónica se opusieran a los deseos anexionistas de los vecinos de los turcos, sin embargo, su comportamiento inspiraba profundas enemistades.

Durante siglos las relaciones entre los judíos y los turcos habían sido buenas. Por el contrario, ya desde cuatro años antes de las guerras balcánicas las relaciones de los judíos con los griegos habían empezado a enfriarse. El 15 de septiembre de 1908 el diario Fharos tis Thessalonikis publicaba un virulento artículo invitando a los griegos a declarar la guerra económica a los judíos. Lo mismo hicieron algunos periódicos más marcadamente antisemitas como Makedonía y O Tajidromos.

La entrada de las tropas griegas en Salónica el 8 de noviembre de 1912, en la primera guerra balcánica, fue considerada por los judíos como una catástrofe. La población fue saqueada en su totalidad y su hinterland, desmembrado. Los israelitas de Salónica pidieron ayuda a las autoridades internacionales para evitar que la ciudad fuese anexionada por los griegos, como así ocurrió al finalizar las guerras balcánicas en 1913, tras el Tratado de Bucarest ${ }^{6}$. Según los judíos,

${ }^{6}$ Lory, B. (1993). «1912, les Hellènes entrent dans la ville», en Salonique, 1850-1918. La «ville des juifs» et le réveil des Balkans, 247-254. 
la helenización de la ciudad supondría no solo el declive económico sino también político, manifestándose claramente el antisemistimo7.

Josef Cohen, profesor de la escuela de la Alianza Israelita Universal escribía a su superior en París:

"Está hecho...y tan pronto como los turcos han abandonado la ciudad el antisemitismo ha alzado su fea cabeza con la entrada de los primeros soldados griegos en la población... Ha habido acusaciones contra los comerciantes judios que han estado vendiendo agua envenenada a los soldados griegos... El antisemitismo siempre ha sido así, que siempre adopta esta forma que acaba dando lugar a masacres" $"$.

Hasta entonces, los judíos formaban un grupo eminentemente visible y distinto, representaban más de la mitad de la población y dominaban la vida económica de Salónica, hasta el punto que las tiendas cerraban los sábados, pues la mayor parte de los cafés, restaurantes, talleres, almacenes, etc. vivían de la clientela israelita9.

Los problemas empezaron para los judíos después de la ratificación del Tratado Greco-Turco de 1913 por el que se abolía el Régimen de las Capitulaciones y todos los privilegios derivados del mismo que venían gozando los judíos en el Imperio otomano ${ }^{10}$. Los judíos desconfiaban de la administración griega, a pesar de las buenas palabras del jefe de gobierno, Venizelos, para convencerlos de los beneficios de la dominación griega ${ }^{11}$. No en vano, el mandatario cretense adoptó una serie de medidas para favorecer a los judíos, entre las que cabría destacar la exención de los israelitas del

${ }^{7}$ Molho, R. (2008). Salonica and Istanbul: Social political and cultural aspects of Jewish life. Isis, Istanbul, 219.

${ }^{8}$ Morcillo, M. (1997). “La comunidad sefardita de Salónica después de las guerras balcánicas (1912-1913)”, Sefarad, año 52, fasc. 2, C.S.I.C. Madrid, 313.

${ }^{9}$ Dumont, P. (1980). «La structure sociale de la communauté juive de Salonique à la fin du dixneuvième siècle», Revue Historique 263, Paris, 353.

${ }^{10}$ Bowman, S. (2002). Jews, en Clogg, R. (ed.). Minoritiesin Greece, Londres, Hurst, IV, 64-93.

${ }^{11}$ Morcillo, M. (1997). «Essai sur la communauté séfardie de Salonique pendant le premier tiers du XXe. Siècle». The Jewish Communities of South-Eastern Europe. From the fifteenth century to the end of World War II, Tessaloniki, 354; Archivo Ministerio Asuntos Exteriores (AMAE). Correspondencia (Grecia), legajo 1604: Despacho dirigido por el cónsul de España en Salónica al ministro residente de España en Grecia (Salónica, 2 enero 1915). 
servicio militar, sin perder el derecho a voto, a cambio de pagar una cierta cantidad de dinero durante tres años; el derecho a llevar las cuentas en su propia lengua (judeoespañol); derecho a participar en la administración pública; permiso para respetar el sabat en Salónica; etc ${ }^{12}$.

Por ello, los israelitas siguieron descansando el sábado y trabajando los domingos hasta 1917, cuando el gobierno griego introdujo la Ley del descanso dominical en Tracia y Macedonia incluida Salónica. Naturalmente, los judíos rechazaron la Ley, que fue cancelada por Venizelos un día después. Los casi 80.000 judíos, frente a los 40.000 griegos y los 5.000 búlgaros, se hallaban en una mejor posición para revocar cualquier ley, dado que eran mayoría ${ }^{13}$. Lo mismo ocurrió con una ley similar aprobada en 1919 que fue suprimida, justo una semana después de haber sido aplicada.

Ese mismo año, en las negociaciones de la Conferencia de Paz de 1919 en París, las delegaciones judías, viendo el peligro que supondría la implantación del descanso dominical en Salónica, pidieron la inserción de un artículo en el tema del Tratado sobre las minorías griegas. La demanda no fue admitida por deferencia a la solemne promesa de Venizelos, según la cual en Salónica la Ley del descanso dominical no sería aplicada a las minorías.

En 1921 el Estado griego impuso el descanso dominical para todas las ciudades de Macedonia y Tracia, excepto Salónica, con la consiguiente protesta de la comunidad judía de Cavala, aunque poco después fue anulado.

Sin embargo, empezaba un nuevo periodo con la llegada de los refugiados de Asia Menor -tras el intercambio de poblaciones en $1922^{14}$, a Salónica,

${ }^{12}$ Morcillo, M. (1997). "La comunidad sefardita de Salónica después de las guerras balcánicas (1912-1913)", 312. Véanse los artículos de Molho, R. (1996). "Venizelos and the Jewish community of Salonika (1912-1919)", Journal of the Hellenic Diaspora 13, Thessaloniki, 113; y (1988). "The Jewish community of Salonika and its incorporation into the Greek State, 19121919", Middle Eastern Studies 24, 391-403; Mazower, M. (2006). Zessaloniki. La ciudad de los fantasmas. Cristianos, musulmanes y hebreos, 1430-1950. Traducción Kostas Kuremenos, Atenas; Mazower, M. (2011). La ciudad de los espíritus. Salónica desde Soleimán el Magnifico hasta la ocupación nazi. Traducción Santiago Jordán, Crítica, Barcelona.

${ }^{13}$ Pierron, B. (1996). Juifs et chrétiens de la Grèce Moderne, L'Harmattan, Paris, 158-164.

${ }^{14}$ Vacalópoulos, A.E. (2005), Historia de la Grecia Moderna, 1204-1985. Traducción Zorbas, N. N. A. Santiago de Chile, 293; Hirschon, R. (1989). Heirs of the Greek Catastrophe. The social life of Asia Minor. Refugees in Piraeus Oxford. 
Macedonia y Tracia ${ }^{15}$. Anteriormente, los judíos constituían el 70\% de la población; ahora, tras el intercambio de poblaciones, solo el $25 \%$.

Los numerosos refugiados pronto forzarían el cambio. En el pasado, los israelitas representaban un enclave económico en las ciudades grecocristianas; en el presente, los refugiados veían en los judíos unos competidores. Por su parte, Venizelos, aprovechando el cambio demográfico en Salónica y olvidando sus promesas propuso en 1922 la Ley pública n ${ }^{\circ} 236$, que obligaba a los judíos de la ciudad a descansar obligatoriamente los domingos.

La medida originó la protesta del gran rabino, el Consejo comunal israelita y los periódicos francófonos de la ciudad que trataron de impedirla al amparo de la Ley 180, basada en el Real Decreto de 5 de abril de 1914, según la cual las ciudades pobladas por otras religiones y gentes por un decreto tendrían derecho a descansar otro día distinto al domingo, por lo que Venizelos tuvo que retirar su propuesta. Y lo mismo ocurrió un año después, argumentando los judíos la Sección 2466 de un Real Decreto de abril de 1923, por la cual los judíos tenían derecho a descansar el sábado, en vez del domingo.

Sin embargo, con el cambio de régimen de monarquía a república en marzo de 1924, el Consejo municipal de Salónica a primeros de mayo de 1924, tras votación, solicitaba al gobierno republicano de Papanastasíu la aplicación de la Ley del descanso dominical en Salónica ${ }^{16}$. La Asamblea Nacional de Grecia votaba el Proyecto de la Ley del descanso dominical en junio de 1924.

El nuevo gobierno republicano de Mijalocópulos -tras la dimisión de Papanastasíu en agosto de $1924^{17}$, a la vista de las numerosas protestas, presentó un Proyecto de Ley con algunas modificaciones en la Ley del descanso dominical, que sería anulado poco después tras el golpe de Estado del general Pángalos el 25 de junio de 1925.

${ }^{15}$ Morcillo, M. (2006). "El desastre de Asia Menor y el conflicto de las minorías nacionales. La cuestión del término 'establecidos”, en Constantinopla: 550 años desde su caída, Granada, III, 157-170.

${ }^{16}$ Josua Elli, P. (2000). Greek Jewry in the 20th century, 1913-1983: Patterns of Survival in the Greek, provinces before and after the Holocaust, 39-40, en línea: http://books.google.es; Archivos Alianza Israelita Universal (París)= AAIU Grèece II, bobine 13, L'Indépendant, (Salónica, 2 julio 1924), 1.

${ }^{17}$ Morcillo, M. (2009). «Conflictividad político-social en Salónica durante la República. De Papanastasíu al general Pángalos (1924-1926)», Estudios neogriegos, 12, País Vasco, 65. 


\subsection{El Consejo municipal de Salónica demanda la aplicación de la Ley del descanso dominical en la ciudad: protestas}

Con la proclamación de la república en Grecia en 1924, los gobiernos de Papanastasíu y Mijalocópulos ${ }^{18}$ no tardaron en perjudicar los intereses económicos de los judíos al implantar la Ley del descanso dominical en Salónica, modificando la Ley de 5 de abril de 1914 que solo se había implantado en Atenas, El Pireo, Patras y Volo, pues en Salónica, dado el alto porcentaje de población israelita en 1914, un 70\%, nunca había sido posible su aplicación, a pesar de varios intentos ${ }^{19}$. Ahora, en 1924, las circunstancias eran diferentes, pues el elemento judío era una minoría con respecto a la población griega, habida cuenta la llegada a Salónica en 1922 de refugiados griegos procedentes de Asia Menor.

El 7 de mayo de 1924 el Consejo municipal, con el voto en contra de los diputados israelitas, aprobó solicitar al gobernador general Vallalas la aplicación de la Ley del descanso dominical en Salónica, que afectaba a todos los ciudadanos, sin distinción de raza ni religión. Tal medida provocará una oleada de protestas en la prensa francófona judía de la ciudad, y el impacto será tan grande en la comunidad hebrea que, a partir de ese momento, la prensa será el instrumento principal de los judíos para manifestar su malestar.

Según L'Indépendant, la decisión adoptada en mayo de 1924 por el Consejo municipal de Salónica había producido una emoción y un sentimiento de indignación indescriptible entre los judíos. Su dolor era mayor, si cabe, pues entre los 17 consejeros municipales cristianos no había habido ninguno que reconociera que esta medida socavaría las bases de la existencia de una gran parte dela población judía o la forzaría, en contra de sus convicciones más íntimas y más sagradas, a trabajar el sábado ${ }^{20}$.

Al conocerse la votación se produjo la protesta unánime del Mouvement Cercle Sioniste y Ligue des Femmes Juives de la Grèce, que habían conocido con amargura e indignación la decisión antiliberal tomadapor el Consejo municipal ${ }^{21}$.

Por otro lado, se reunía la Asamblea comunal israelita para tratar la decisión adoptada por el Consejo municipal y, tras protestar enérgicamente, decidió

\footnotetext{
${ }^{18}$ Morcillo, M. «Conflictividad político-social en Salónica», 59.

${ }^{19}$ Pierron, B. (1996). Juifs et chrétiens de la Grèce Moderne, 159.

${ }^{20}$ Díaz-Mas, P. (1997). Los sefardies. Historia, lengua y cultura ( $3^{\text {a }}$ ed.). Barcelona, 32-33.

${ }^{21}$ L'Indépendant (Salónica, 8 mayo 1924), 1.
} 
enviar una carta abierta, publicada en el diario L'Indépendant, al presidente del Consejo nacional, Papanastasíu, recordándole que en su reciente visita a Salónica había adquirido el compromiso de interceder en la cuestión del descanso dominical. Por ello, pedían al presidente que mantuviera el statu quo para los israelitas y la instauración del descanso dominical para los cristianos.

Aunque los periódicos griegos también se ocupaban del descanso dominical, el director de L'Indépendant se extrańaba del poco empeño que ponían los diarios helenos en profundizar en esta cuestión y no querer comprender las razones religiosas, sentimentales y nacionales que poseían los israelitas para rechazar esta medida que perjudicaba a sus derechos y a sus intereses étnicos.

Según L'Indépendant, el diario To Fos era, con el Imerisia, el que había observado hasta ese momento la actitud más correcta en esta cuestión. Sin entrar en el fondo del debate, ToFos se contentaba con señalar solamente que los judíos habían hecho mucho ruido sobre este tema, y que no era el mejor medio de defender la causa que consideraban justa ${ }^{22}$.

También, el cónsul de España en Salónica, Teodoro Varela, se hacía eco de la cuestión del descanso dominical y transmitía al gobierno español el malestar de los judíos sefardíes por el posible perjuicio causado a sus intereses económicos, y animaba a los comerciantes a que se acogiesen al reciente Decreto de Primo de Rivera de marzo 1924 que otorgaba la nacionalidad española a los 'antiguos protegidos españoles o descendientes de éstos y, en general, a individuos pertenecientes a familias de origen español' que solicitasen la nacionalidad antes del 31 de diciembre de 1930, y poder así regresar a España. Pero para entonces, muy pocos estaban interesados ${ }^{23}$. Después, se lamentarían de ello ${ }^{24}$.

Al dolor que sentía la comunidad judía, había que añadir lo sucedido con un grupo de refugiados de Asia Menor que había recorrido las principales arterias de la ciudad obligando a los israelitas a cerrar sus establecimientos ${ }^{25}$.

${ }^{22}$ To Fos, citado en L'Indépendant (Salónica, 11 mayo 1924), 1.

${ }^{23}$ Morcillo, M. (1997). "La comunidad sefardita de Salónica”, 324.

${ }^{24}$ Morcillo, M. (2008). S.R. Radigales y los sefardies de Grecia, 1943-1946. (Coedirs.) Casa Sefarad, Instituto Cervantes de Atenas y Universidad de Castilla-La Mancha, Madrid.

${ }^{25}$ L'Indépendant (Salónica, 11 mayo 1924), 1. 


\subsection{La Asamblea Nacional vota la Ley 3103 sobre el descanso dominical: reacciones}

\subsubsection{Asociaciones judías}

Una vez aprobada la aplicación de la Ley del descanso dominical en Salónica por el Consejo municipal, tocaba ahora debatir y votar en la Asamblea Nacional la nueva Ley 3103 sobre la aplicación de las 'disposiciones del Real Decreto de 5 de abril de 1914'.

Los diputados Jadsikiriakos, Curtidis, Anastasiadis y Gonatás pidieron que el gobierno extendiera las disposiciones de la Ley del descanso dominical a todas las áreas urbanas del Estado y, particularmente, a la ciudad de Salónica ${ }^{26}$. La Asamblea Nacional votó la nueva Ley comprometiéndose a presentar pronto en la Cámara un Proyecto de Ley sobre esto, que finalmente sería aprobado en junio de $1924^{27}$.

La protesta de la comunidad israelita fue unánime, culpando de ello a la intolerancia municipal, al gobierno y al antisemitismo. Los primeros en manifestar su malestar fueron las organizaciones sionistas de Salónica reunidas en asamblea general el 5 de julio de 1924. El diario L'Indépendant fue el portavoz de sus protestas:

Le Nouveau Club Sioniste, representando una gran parte del cuerpo comercial y del mundo intelectual judío de Salónica, protestaba contra esta medida incalificable que violaba la conciencia de 80.000 personas que habían sido los L’Organisation Sioniste Béne $B_{\text {érith }}^{28}$, considerando que este Proyecto que acababa de ser votado en la Asamblea Nacional iba en contra de las ideas de tolerancia religiosa contenidas en la constitución griega rechazaba dicha Ley por antiliberal.

L'Association 'Théodore Herzl' protestaba igualmente contra la Ley del descanso dominical por violar sus principios más sagrados y pedía al gobierno de Atenas que retirase el Proyecto. L'Association des 'Jeunes Juifs 'veía en esa medida de intolerancia religiosa el preludio de una persecución sistemática

\footnotetext{
${ }^{26}$ AAIU, Greece II, bobine 13, L'Opinion (Salónica, 24 mayo 1924), 1.

${ }^{27}$ AAIU, Greece II, bobine 13, Le Progrès (Salónica, 19 junio 1924), 1.

28 'Béne Bérith' (Hijos de la Alianza). Organización filantrópica judía.
} 
contra los judíos de Salónica, y L'Association des 'Anciens Élèves' de L'AIU de Salónica pedía al gobierno que la libertad de conciencia fuese respetada.

L'Organisation Sioniste 'Mizrachi' lucharía hasta el final para el reconocimiento integral de los derechos imprescriptibles de las minorías nacionales ${ }^{29}$. Por su parte, L'Association Sioniste 'Béné Israél '30 pedía que tal Proyecto no entrase en vigor. Lo mismo haría Le Club des Intimes.

La Société 'Max Nordau'31, compuesta exclusivamente por obreros y artesanos, protestaba contra la Asamblea Nacional que había aceptado en principio el Proyecto sobre el descanso dominical obligatorio, sin tener en cuenta los derechos de una minoría étnica de 80.000 personas.

Por su parte, los miembros de la Asamblea comunal y del Consejo rabínico de la comunidad israelita decidieron que las sinagogas permaneciesen cerradas hasta nueva orden en señal de protesta. Las llaves de dichas sinagogas serían remitidas al gobernador general.

\subsubsection{Prensa griega}

También, la prensa francófona recogía opiniones de los diarios griegos sobre el descanso dominical. El diario Eléfceros Tipos escribía bajo el título "Exilio o lucha” que el periódico israelita Pro Israel de Salónica había publicado un violento artículo contra la aplicación del descanso dominical en la capital de Macedonia, Salónica ${ }^{32}$. El diario griego criticaba la postura intransigente de los judíos y señalaba que eldescanso dominical obligatorio no era una medida antirreligiosa, sino económica ${ }^{33}$.

La última hora sobre el descanso dominical que recogía la prensa griega era favorable a la causa judía. El diario Politia acusaba al gobierno de querer instituir por la fuerza el descanso dominical en Salónica y a Papanastasíu de olvidar que había formado parte del ejecutivo de Venizelos, el cual estaba a favor de la creación de un Estado judío en Palestina.

\footnotetext{
${ }^{29}$ L'Indépendant (Salónica, 6 julio 1924), 1.

30 'Béné Israél' (Hijos de Israel). Organización de judíos de la India con mucha influencia por el apoyo británico.

${ }^{31}$ Max Nordau fue uno de los fundadores del Movimiento Sionista.

32 Morcillo, M. (1997). "La comunidad sefardita de Salónica”, 312.

${ }^{33}$ ElefthérosTypos, citado en L’Indépendant (Salónica, 7 julio 1924), 1.
} 
Por su lado, el diario Eléfceron Vima señalaba que el gobierno debía hacer todas las concesiones posibles a la minoría judía, que era un elemento trabajador y contribuía a la prosperidad del país. Por el contrario, el diario Dimocratía escribía que el ruido hecho en torno al descanso dominical era injustificado ${ }^{34}$.

En cualquier caso, las organizaciones judías tenían la convicción que el movimiento a favor del descanso dominical fue puesto en marcha por algunos agitadores antisemitas que habían envenenado a la opinión pública y habían arrastrado a otros, sin olvidar la presión de los refugiados y el miedo del gobierno a perder sus votos. No en vano el $70 \%$ de los refugiados votaron a favor de la república ${ }^{35}$.

\subsection{Publicación oficial y entrada en vigor de la Ley 3103: justificación}

El ministro de Economía Dousinas informaba al gobernador general, al comandante de la Gendarmería y al inspector de policía de Salónica que la Ley 3103, votada recientemente en la Asamblea Nacional sobre la aplicación de 'las disposiciones del Real Decreto de 5 de abril de 1914', había sido publicada en el $\mathrm{n}^{\mathrm{o}} .165$ del Diario Oficial el 21 de julio de $1924^{36}$, para que tomasen las medidas necesarias para la aplicación integral del descanso dominical en Salónica.

Por esta Ley, el 1er. párrafo del artículo 26 de la Ley 2456 sobre comunidades israelitas, así como el segundo párrafo del artículo I del Real Decreto de 5 de abril de 1914, eran derogados 'ipso jure'. Las otras disposiciones entrarían en vigor inmediatamente y deberían ser observadas por todos los ciudadanos, sin distinción de raza ni religión. El Decreto de 5 de abril de 1914 debería ser aplicado íntegramente.

Excepcionalmente, y hasta el final de diciembre de 1924, la apertura de los establecimientos comerciales sería autorizada los domingos de 10 a $12 \mathrm{~h}$. La ley entraría en vigor al día siguiente de su publicación en el Diario Oficial.

El Decreto-Ley iba acompañado por un informe explicativo del ministro de Economía Dousinas en el que decía, entre otras cosas, que mientras la Ley

\footnotetext{
${ }^{34}$ L'Indépendant (Salónica, 13 julio 1924), 1.

${ }^{35}$ Cabo I. (2005). Turquia, Grecia y Chipre: historia del Mediterráneo oriental, Barcelona, 147-148; Linfield, H.S. (2011). A Survey of the year 5685. Jewish spiritual and intellectual life, en línea: http://www.ajcarchives.org/AJC_DATA/Files/1926_1927_3_YearReview.pdf. 21-24.

${ }^{36}$ Le Progrès (Salónica, 22 julio 1924), 2.
} 
del descanso dominical había sido extendida y aplicada hasta el momento en casi todas las ciudades y muchos colectivos del resto de Grecia, no había sido posible aplicarla en Salónica y en las otras grandes ciudades de Macedonia y Tracia en razón de la oposición de los elementos no cristianos. Ahora, y desde hacía tres meses, todas las organizaciones griegas y autoridades municipales de Macedonia y Tracia, los refugiados de Asia Menor y, en general, toda la población griega venía pidiendo con insistencia implantar en estas regiones la Ley del descanso dominical para todos los ciudadanos sin distinción ${ }^{37}$.

El 1 de enero de 1925 el Consejo municipal aprobaba por unanimidad, con la ausencia de los consejeros israelitas, la aplicación íntegra de la Ley del descanso dominical en Salónica. Había terminado el plazo al que aludía la Ley 3103 por la que excepcionalmente, y hasta el 31 de diciembre de 1924, los comercios podrían seguir abriendo dos horas los domingos. Finalmente, el Decreto Ley fue publicado el 13 de mayo de 1925. Según Le Progrès la Ley del descanso dominical obligatorio entraría en vigor en Salónica a partir del domingo próximo siguiente a su publicación ${ }^{38}$.

Dicha Ley señalaba que durante los domingos y las fiestas de Navidad, la Anunciación y el lunes de Pascua ortodoxos estaba prohibido trabajar. Pero había excepciones generales en las que la Ley no se aplicaría: los trabajadores agrícolas, pescadores, transportistas, obreros de fábricas de productos perecederos, restaurantes, floristerías, servicios de medicina, maternidad, hospitales, servicios de pompas fúnebres y enterramientos, tabernas, pequeños restaurantes, coloniales, lecherías, panaderías, peluquerías, expendedurías y farmacias, que abrirían por turnos, etc.

Quedaba autorizada la apertura de los establecimientos el 31 de diciembre. El incumplimiento de la Ley del descanso dominical sería castigado de 3 a 30 días de cárcel y una multa de hasta 500 dracmas. En caso de reincidencia, la pena sería doble. El establecimiento donde se contraviniera la orden sería cerrado durante todo el día.

La revista sionista Pro Israel fue la primera en denunciar que Grecia, con esta medida, violaba sus acuerdos ${ }^{39}$. Después, se convocó una gran manifestación judía para protestar. En el templo de Beth Saul el gran rabino, Emmanuel Brudo,

${ }^{37}$ L'Indépendant, (Salónica, 2 y 22 de julio 1924), 1.

${ }^{38}$ Le Progrès (Salónica, 22 mayo 1925), 1-2.

${ }^{39}$ AAIU, Greece II, bobine 13, Pro Israel (Salónica 22 y 28 mayo 1925), 1. 
habló del descanso sabático como la base intangible de la ley mosaica y terminó haciendo un llamamiento a todos los judíos para que permaneciesen fieles a la sagrada costumbre.

Por su parte, varios miembros del Consejo comunal israelita, entre los que se encontraban León Gattegno, Elie Benusiglio, David Matalon, Samuel Botton, Menahem Halton, Benico Saltiel, Asher Mallah, Joseph-Béraha, Abraham Recanati y Jacques Nahamias, dirigían un manifiesto a los judíos diciéndoles que la imposición del descanso dominical en Salónica situaba a la población judía en la cruel alternativa de elegir entre traicionar uno de los principios más sagrados, su religión, o su ruina económica ${ }^{40}$.

\subsection{Proyecto de modificación de la Ley del descanso dominical.}

Aunque, hasta el momento, habían sido inútiles todas las peticiones en favor de la derogación de la Ley del descanso dominical obligatorio en Salónica, al menos sirvieron para que el gobierno aprobara una circular sobre modificación de dicha Ley ${ }^{41}$.

Spirides, nuevo ministro de Economía, a la vista de las sugerencias hechas por todas las organizaciones obreras y patronales del país, consideró la oportunidad de aportar algunas modificaciones a la Ley del descanso dominical en vigor. Respecto a los judíos de Salónica, Spirides pensaba constituir una comisión compuesta por los diputados griegos M. Jadsikiriacos y Kicros, y los delegados de la comunidad israelita Saias, Botton y Simantov Sciaky, presidida por el nuevo gobernador general, Cannovos. Dicha comisión tendría como objetivo buscar un 'modus vivendi'que conciliase todos los intereses.

Sin embargo, a principios de enero de 1925, todavía no se había reunido la comisión por la ausencia de delegados municipales. No obstante, Spirides había prometido que haría todo lo posible para que los comerciantes judíos pudieran trabajar cuatro horas los domingos y los artesanos y obreros, también judíos, seis o siete horas ${ }^{42}$.

Le Progrès publicaba el Proyecto de Spirides el 18 de junio de 1925. Según este Proyecto, se permitiría abrir las tiendas de 10-14 h. en las localidades de 8.000 habitantes solamente ${ }^{43}$. Spirides justificaba su Proyecto argumentando

${ }^{40}$ Le Progrès (Salónica, 25 mayo1925), 1.

${ }^{41}$ Le Progrès (Salónica, 15 noviembre1924), 1.

${ }^{42}$ L'Indépendant (Salónica, 19 mayo 1925), 1. 
que la aplicación del descanso dominical durante una decena de años había demostrado que la Ley no era perfecta y que, por consiguiente, era necesario modificarla y completarla.

Sin embargo, unos días después, el 25 de junio de 1925, el general Pángalos daba un golpe de Estado, implantaba una dictadura militar y, tras un plebiscito, se convertía en presidente de la República ${ }^{44}$. El cambio de gobierno beneficiaría en parte a los judíos, pues Pángalos emitió un decreto que permitía a los israelitas de Salónica abrir las tiendas tres horas los domingos ${ }^{45}$, anulando por tanto, el Proyecto de Spirides. Los judíos que no aceptaron el descanso dominical obligatorio marcharon a Palestina y Francia ${ }^{46}$.

\section{Conclusiones}

Resulta doloroso pensar en la facilidad con la que la cuestión del descanso dominical se había solucionado después de la gran campaña de prensa que había apasionado a la opinión pública salonicense y que había aumentado en varios centenares de números la circulación de periódicos que aparecían cada día en Salónica.

Al final, muchas discusiones y protestas en publicaciones oficiales y privadas, revistas y periódicos. Esto es lo que había tenido en vilo a la población judía de Salónica durante más de 18 meses. El resultado había sido, sin embargo, en vano. La ley del descanso dominical obligatorio se había aplicado en la ciudad de forma íntegra, a pesar de las promesas ministeriales, a pesar de toda la buena voluntad del gobernador general, Cannovos y, en definitiva, de todos aquellos que, aun comprendiendo que los judíos tenían razón en sus protestas, se dejaron llevar por ciertos intereses.

En definitiva, la intolerancia del Consejo municipal de Salónica y la debilidad del gobierno republicano griego de Papanastasíu por la pérdida de votos de los refugiados de Asia Menor, junto con el antisemitismo exacerbado que se venía respirando en Salónica desde su incorporación al Estado griego en 1913 -aunque bien es verdad que ya desde la constitución del reino de Grecia en 1830 se podía hablar de antisemitismo-, agudizado tras el incendio de la ciudad en 1917, sin olvidar el papel desempeñado por la prensa antisemita griega, en particular el diario Makedonía, conforman el contexto histórico en el que se aplicó la Ley del descanso dominical obligatorio en Salónica en 1924.

${ }^{43}$ Le Progrès (Salónica, 18 junio1925), 1.

${ }^{44}$ Morcillo, M. (2009).“Conflictividad político-social en Salónica durante la República”, 67.

${ }^{45}$ Linfield, H.S. (2011). A Survey of the year 5685. Jewish spiritual and intellectual life, 21-24.

${ }^{46}$ Josua Eli, P. (2000). Greek Jewry in the 20th century, 1913-1983: Patterns of Survival in the Greek, provinces before and after the Holocaust, 41. 


\section{Referencias bibliográficas}

Benbasa, E. y Rodrigue, A. (1993). Les Juifs des Balkans, espaces judeoibériques, Paris, 271 y 287.

Bowman, S. (2002). Jews, en Clogg, R. (ed.). Minoritiesin Greece, Hurst, IV, Londres, 64-93.

Cabo, I. (2005). Turquí, Grecia y Chipre: historia del Mediterráneo oriental, Barcelona, 147-148.

DíAz-MÁs, P. (1997). Los sefardies. Historia, lengua y cultura (3a ed.). Barcelona, 32-33.

Díaz-Mas, P. (2007). "Relaciones entre la prensa española y la prensa sefardí a finales del siglo XIX: El caso del Luzero de la pasensia”, en Ayer y hoy de la prensa en judeoespañol, Isis, Estambul, 38-39.

Dumont, P. (1980). "La structure sociale de la communauté juive de Salonique à la fin du dix-neuvième siècle», Revue Historique 263, Paris, 353.

Hirschon, R. (1989). Heirs of the Greek Catastrophe. The social life of Asia Minor. Refugees in Piraeus. Oxford.

Josua Elli, P. (2000). Greek Jewry in the 20 th century, 1913-1983: Patterns of Survival in the Greek, provinces before and after the Holocaust, 39-40, en línea: http://books.google.es

Linfield, H.S.(2011). A Survey of the year 5685. Jewish spiritual and intellectual life, en línea: http://www.ajcarchives.org/AJC_DATA/ Files/1926_1927_3_YearReview.pdf. 21-24

Lory, B. (1993). «1912, les Hellènes entrent dans la ville», en Salonique, 1850-1918. La «ville des juifs» et le réveil des Balkans, (dir.) Veinstrin, G. Paris, 247-254.

Mazower, M. (2006). Zessaloniki. La ciudad de los fantasmas. Cristianos, musulmanes y hebreos, 1430-1950. Traducción Kostas Kuremenos, Atenas.

Mazower, M. (2011). La ciudad de los espiritus. Salónica desde Soleimán el Magnifico hasta la ocupación nazi. Traducción Santiago Jordán, Crítica, Barcelona.

Molmo, R. (1996). "Venizelos and the Jewish community of Salonika (1912-1919)", Journal of the Hellenic Diaspora 13, Thessaloniki, 113.

Molno, R. (1988). "The Jewish community of Salonika and its incorporation into the Greek State, 1912-1919”, Middle Eastern Studies 24, 391-403. 
Molno, R. (2008). Salonica and Istanbul: Social political and cultural aspects of Jewish life. Isis, Istanbul.

Morcillo, M. (1991). "Hispania, primera revista española en Oriente (1919)" Ensayos, 5, Escuela de Magisterio, Albacete, 71-77.

Morcillo, M. (1997). "Essai sur la communauté séfardie de Salonique pendant le premier tiers du XXe. Siècle ». The Jewish Communities of South-Eastern Europe. From the fifteenth century to the end of World War II, Tessaloniki, 354.

Morcillo, M. (1997). "La comunidad sefardita de Salónica después de las guerras balcánicas (1912-1913)”, Sefarad, año 52, fasc. 2, C.S.I.C. Madrid, 312.

Morcillo, M. (2006). "El desastre de Asia Menor y el conflicto de las minorías nacionales. La cuestión del término 'establecidos", en Constantinopla: 550 años desde su caida, Granada, III, 157-170.

Morcillo, M. (2007). "España y la prensa judeoespañola en Salónica durante el primer tercio del siglo XX", en Ayer y hoy de la prensa en judeoespañol, Isis, Estambul, 47-57.

Morcillo, M. (2008). S.R. Radigales y los sefardies de Grecia, 1943-1946. (Coedirs.) Casa Sefarad-Israel, Instituto Cervantes de Atenas y Universidad de Castilla-La Mancha, Madrid.

Morcillo, M. (2009). "Conflictividad político-social en Salónica durante la República. De Papanastasíu al general Pángalos (1924-1926)”, Estudios neogriegos, 12, País Vasco, 59-72.

Nehama, J. (1978). Histoire des Israélites de Salonique, VI-VII, Salonique.

Pierron, B. (1996). Juifs et chrétiens de la Grèce Moderne, L'Harmattan, Paris, 158-164.

Rodrigue, A. (1989). De l'instruction à l'émancipation.Les enseignants de l'Alliance israélite universelle et les Juifs d'Orient, 1860-1939, Paris.

Romero, E. (2007) "La prensa judeoespañola contra los recelos, la burocracia y la censura”, en Ayer y hoy de la prensa en judeoespañol, (eds.) Pablo Martín Asuero y Karen Gerson Sarhon, Isis, Estambul, 9-10.

Romero, E. (2008). Entre dos (o más) fuegos: Fuentes poéticas para la historia de los sefardies de los Balcanes, C.S.I.C., Madrid, 731.

Vacalópoulos, A E. (2005), Historia de la Grecia Moderna, 1204-1985. Traducción Zorbas, N. N. A. Santiago de Chile, 293. 